\title{
THE FISHERY AND REPRODUCTIVE BIOLOGY OF BARKING CRAYFISH, LINUPARUS TRIGONUS (VON SIEBOLD, 1824) ALONG QUEENSLANDSEAST COAST
}

\author{
BY \\ J. A. HADDY ${ }^{1}$ ), D. P. ROY and A. J. COURTNEY \\ Queensland Department of Primary Industries, Southern Fisheries Centre, P.O. Box 76, \\ Deception Bay, Qld 4508, Australia
}

\begin{abstract}
This paper describes the fishery and reproductive biology for Linuparus trigonus obtained from trawl fishermen operating off Queensland's east coast, Australia. The smallest mature female lobster measured $59.8 \mathrm{~mm} \mathrm{CL}$, however, 50\% maturity was reached between 80 and $85 \mathrm{~mm} \mathrm{CL}$. Brood fecundity (BF) was size dependent and ranged between 19,287 and 100,671 eggs in 32 females from 59.8 to $104.3 \mathrm{~mm} \mathrm{CL}$. The relationship was best described by the power equation $\mathrm{BF}=$ $0.1107 * \mathrm{CL}^{2.9241}\left(\mathrm{r}^{2}=0.74\right)$. Egg size ranged from 0.96 to $1.12 \mathrm{~mm}$ in diameter (mean = $1.02 \pm 0.01 \mathrm{~mm})$. Egg weight and size were independent of lobster size. Length frequencies displayed multi-modal distributions. The percentage of female to male lobsters was relatively stable for small size classes (30 to $70 \mathrm{~mm} \mathrm{CL} ; 50.0$ to $63.6 \%$ females), but female proportions rose markedly between 75 and $90 \mathrm{~mm}(72.2$ to $85.4 \%)$ suggesting that at the onset of sexual maturity female growth rates are reduced. In size classes greater than $95 \mathrm{~mm}$, males were numerically dominant. A description of the L. trigonus fishery in Queensland is also detailed.
\end{abstract}

\section{RÉSUMÉ}

Cette étude décrit les caractéristiques de pêche et la biologie de la reproduction de Linuparus trigonus, obtenu par les pêcheurs au chalut au large de la côte orientale de Queensland, Australie. La langouste mature femelle la plus petite mesurait 59,8 $\mathrm{mm} \mathrm{CL}$, cependant, la maturité à $50 \%$ était atteinte pour les animaux mesurant de 80 à $85 \mathrm{~mm}$ CL. La fécondité $(\mathrm{BF})$ était dépendante de la taille et comprise entre 19,287 et 100,671 œufs chez 32 femelles de 59,8 à 104,3 mm CL. La relation a été le mieux exprimée par l'équation $\mathrm{BF}=0,1107 * \mathrm{CL}^{2,9241}\left(\mathrm{r}^{2}=0,74\right)$. La taille des œufs variait de 0,96 à $1,12 \mathrm{~mm}$ de diamètre (moyenne $=1,02 \pm 0,01 \mathrm{~mm}$ ). Le poids et la taille des œufs n'étaient pas liés à la taille de la langouste. Les distributions de fréquence de longueur ont montré une distribution multi-modale. Le pourcentage des femelles par rapport aux mâles était relativement stable pour les petites classes de taille (30 à $70 \mathrm{~mm}$ CL; 50,0 à 63,6\% de femelles), mais les proportions de femelles ont augmenté de façon marquée pour les classes de taille de 75 à $90 \mathrm{~mm}$ (72,2 à 85,4\%), suggérant

\footnotetext{
1) Corresponding author. Present address: NSW Fisheries Research Institute, P.O. Box 21, Cronulla,
} NSW 2230, Australia; e-mail: James.Haddy@ fisheries.nsw.gov.au 
qu'au début de la maturité sexuelle, les taux de croissance des femelles sont réduits. Pour les classes de taille supérieures à $95 \mathrm{~mm}$, les mâles étaient numériquement dominants. Une description de la pêche au Queensland est également détaillée.

\section{INTRODUCTION}

Barking crayfish, Linuparus trigonus (Von Siebold, 1824), also known as spear or champagne lobster, is one of three extant species of the genus Linuparus, which is one of eight genera of the family Palinuridae (spiny lobsters) (Holthuis, 1991). Unlike most spiny lobsters, Linuparus spp. are generally found in deep water (81-328 $\mathrm{m}$ ) and restricted to the Indo-West Pacific region (Bruce, 1965; Berry \& George, 1972). Linuparus lobsters generally occur in relatively low abundance (Holthuis, 1991), however, L. trigonus occurs in sufficient densities off Townsville, Australia to support a targeted commercial fishery and also contribute as an important by-product throughout the Queensland East Coast Trawl Fishery (QECTF). However, it is currently unknown whether present exploitation levels are sustainable as very little is known about the population dynamics of $L$. trigonus.

Size at sexual maturity and fecundity are some of the most important life history parameters needed for stock assessment and management of sustainable exploitation levels (Chubb, 1994). These parameters can be used with other population parameter estimates such as growth and mortality to develop yield and egg-per-recruit models. Discard mortality of trawl caught crustaceans is relatively low compared to fish (Hill \& Wassenberg, 1990), which enables minimum legal size limits to be effective management strategies. Currently there is no biological information on L. trigonus to establish a minimum legal size. The aim of this study was to describe the fishery and reproductive biology of L. trigonus, to assist in the development of sustainable management strategies.

\section{MATERIALS AND METHODS}

Mandatory logbook data for Linuparus trigonus from 2000-2002 were used to examine the spatial distribution (30 min. grids), total catch, total effort, and catch per unit effort along the Queensland east coast. Pre 2000 data could not be used in the analyses due to taxonomic uncertainties in the recording of lobster data associated with other spiny lobster species.

A sampling program was undertaken between October 2001 and February 2003 and totally relied upon commercial trawl fishers operating between Townsville and Mooloolaba (fig. 1) to donate lobsters. An additional frozen sample of ovigerous females caught in August 2000 was also provided. Lobster sample sizes ranged 


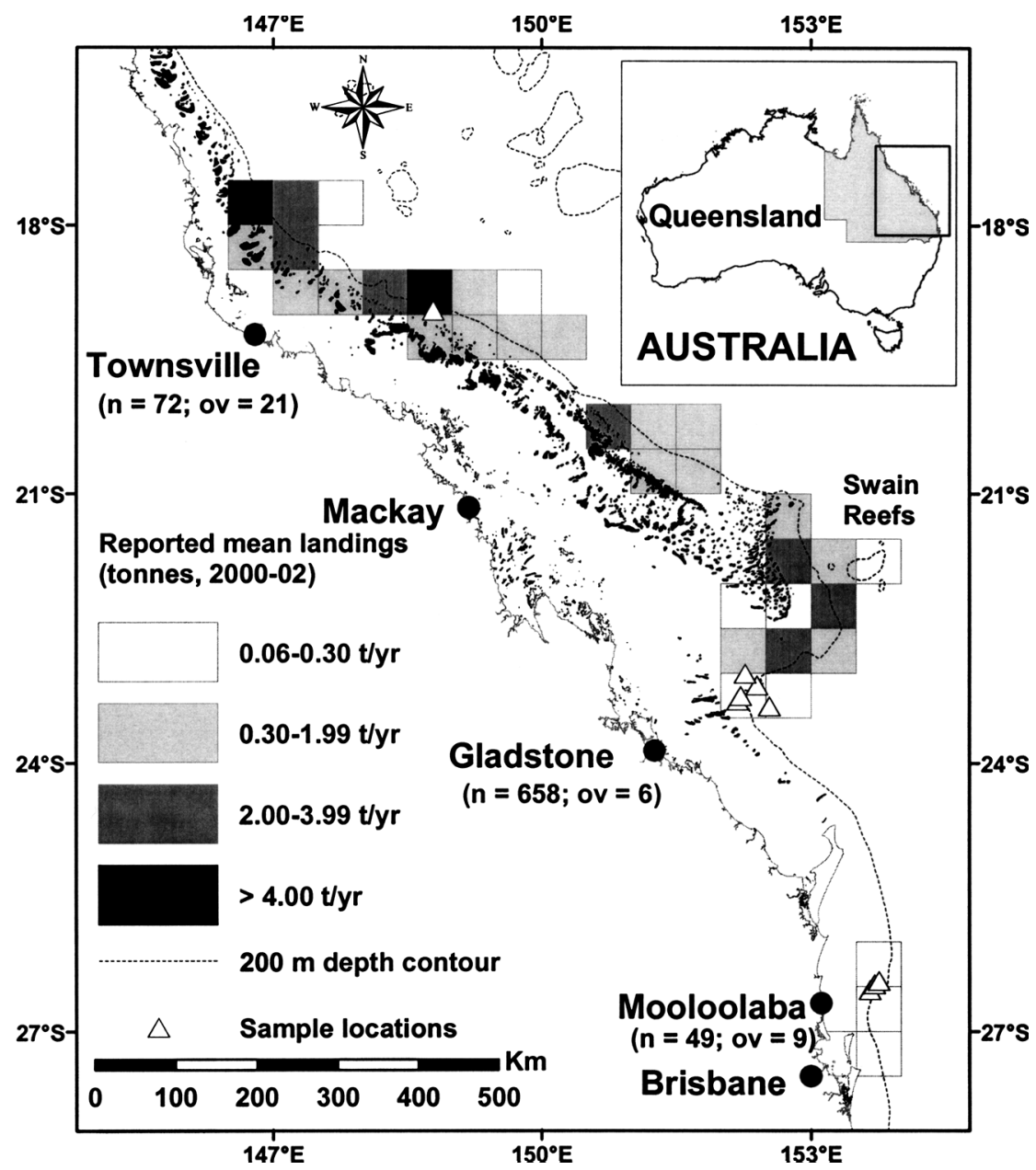

Fig. 1. Spatial distribution of reported mean landings of Linuparus trigonus (Von Siebold, 1824), from the Queensland East Coast Trawl Fishery (2000-2002). Logbook grids that reported $<0.06 \mathrm{t}$ year $^{-1}$ ( $<1 \%$ of reported catches) have been omitted for clarity. Sample numbers (ov $=$ ovigerous) for each location area are detailed in parentheses.

between 7 and 182 individuals and samples were obtained from depths between $120 \mathrm{~m}$ and $238 \mathrm{~m}$. Because the targeted fishing effort for $L$. trigonus is intermittent throughout the year due to fishers targeting other, more valuable stocks, samples were not provided in November 2001 to January 2002, August to September 2002, and December 2002 to January 2003.

Specimens were frozen and stored until processed in the laboratory. Once thawed, total weight (TW; antennal flagella removed), carapace length (CL), sex, gonad weight (females only), macroscopic gonad condition, ovigerous setae, and stage of egg development were recorded. Carapace length was measured between 


\section{TABLE I}

Macroscopic descriptions of gonadal development and mean gonadosomatic indices of Linuparus trigonus (Von Siebold, 1824)

\begin{tabular}{llc}
\hline Stage & Macroscopic description & Mean GSI (range) \\
\hline 1 & Ovaries clear to white, small, straight and narrow. & 0.12 \\
Immature & Individual oocytes not visible. & $(0.05-0.17)$ \\
& & $\mathrm{n}=5$ \\
2 & Ovaries cream to yellow and small. Individual oocytes not & 0.65 \\
Immature/ & visible. & $(0.11-1.23)$ \\
regressed & & $\mathrm{n}=79$ \\
3 & Ovaries orange, enlarged throughout their length but not & 1.62 \\
Maturing & convoluted. Individual oocytes are just visible through the & $(0.69-2.53)$ \\
& ovary wall. & $\mathrm{n}=43$ \\
4 & Ovaries bright orange, swollen, and convoluted filling all & 5.98 \\
Mature & $\begin{array}{l}\text { available space in the cephalothoracic region. Individual } \\
\text { oocytes are clearly visible through the ovary wall. }\end{array}$ & $(2.99-10.14)$ \\
5 & Ovaries cream to yellow/orange, large but not convoluted, & $\mathrm{n}=53$ \\
Spent & with flaccid and granular appearance. A few residual & 1.03 \\
& oocytes can sometimes be seen through the ovary wall. & $(0.19-2.75)$ \\
\hline
\end{tabular}

the mid-point of the sub-orbital horns to the posterior edge of the carapace using graduated Vernier callipers to 0.1 millimetres. Criteria for macroscopic staging of gonads were obtained from Stewart et al. (1997) and are detailed in table I. Extruded eggs were classified as, (1) Early, orange with no pigmentation, (2) Mid, orange with eye-spots visible, or (3) Late, brown with eye-spots visible.

Estimates of brood fecundity were determined using a gravimetric method. Late stage ovigerous females were not used due to the fragility of the eggs. Ovigerous females were placed onto blotting paper and allowed to drain. The entire egg mass was carefully stripped from the pleopods using curved forceps and weighed $( \pm 1 \mathrm{mg})$. Between 20 and $500 \mathrm{mg}$ of the egg mass was subsampled, weighed $( \pm 0.01 \mathrm{mg})$, and fixed in $70 \%$ ethanol. Sub-samples averaged $251.3 \pm 27.21$ (SE) milligrams and varied between 0.23 and $5.88 \%$ of the total egg mass weight (mean $=2.23 \%$ ). Egg clumps in the sub-sample were separated into individual eggs by dissolving the egg stalks with sodium hypochlorite. Once separated, the sub-sample was drained, rinsed, and resuspended in $70 \%$ ethanol, poured into a glass Petri dish and scanned at 300 dpi. The total number of eggs in the sub-sample was then determined using computer image analysis (ImagePro Plus, version 4.5). Fecundity was estimated by simple proportion. The mean diameters of freshly thawed individual eggs were determined from 13 females using a dissecting microscope fitted with a digital camera and measured using image analysis software. Diameter measurements were taken radiating at 2 degree 
intervals for each egg to produce a mean egg diameter. Between 10 and 38 eggs were measured for each female.

\section{RESULTS}

Analysis of logbook data

The spatial distribution of mean annual landings of Linuparus trigonus from 2000 to 2002 is shown in fig. 1. Reported annual landings for the Queensland East Coast Trawl Fishery in 2000, 2001, and 2002 were 103.4, 50.2, and 13.5 tonnes, respectively. The majority of the catch came from seasonal trawling in the deep waters $(>90 \mathrm{~m})$ off Townsville, however, substantial catches were also reported off Mackay and at the Swain Reefs (fig. 2a). Off Townsville and Mackay, total annual effort was 825,294 , and 0 boat days and 131, 3, and 0 boat days in 2000, 2001, and 2002, respectively (fig. 2b). In contrast, total annual effort remained relatively stable at the Swain Reefs and was 3099, 2916, and 3640 boat days for 2000, 2001, and 2002, respectively. Overall, the total catch per unit effort (CPUE) was relatively high off Townsville and Mackay with an average catch rate of 194 and $115 \mathrm{~kg}$ per boat day, respectively, whereas the average catch rate at the Swain Reefs was only $9.15 \mathrm{~kg}$ per boat day (fig. 2c). Small isolated catches were also reported off the south-eastern Queensland coast near Mooloolaba.

Sex ratio and length frequency distributions

A total of 434 females and 345 males was collected. The length frequencies of male and female lobsters (locations pooled) displayed multi-modal distributions (fig. 3). The percentage of female to male lobsters was relatively stable throughout the small size classes (30 to $70 \mathrm{~mm}$ CL) and ranged between 50.0 and $63.6 \%$ females, however, female proportions rose markedly in size classes between 75 and $90 \mathrm{~mm}$ ranging between 72.2 and $85.4 \%$. In size classes greater than $95 \mathrm{~mm}$, males were numerically dominant. Overall, females outnumbered males by $1.19: 1$. The length-weight relationship for males and females (antennal flagella removed) was $\mathrm{TW}=0.00034 * \mathrm{CL}^{2.9812}\left(\mathrm{n}=285, \mathrm{r}^{2}=0.99\right)$, and $\mathrm{TW}=0.00038^{*} \mathrm{CL}^{2.9629}$ $\left(\mathrm{n}=310, \mathrm{r}^{2}=0.99\right)$, respectively.

\section{Size at maturity}

The relationship between female size and ovarian development is detailed in fig. 4. Females smaller than $58 \mathrm{~mm} \mathrm{CL}$ possessed immature ovaries. Thereafter, the proportion of immature stages declined markedly until all females larger than $75 \mathrm{~mm}$ CL possessed ovaries at stage 2 or higher. The smallest sexually mature female (stages 3-5) was $59.8 \mathrm{~mm} \mathrm{CL}$. This individual was ovigerous. The 

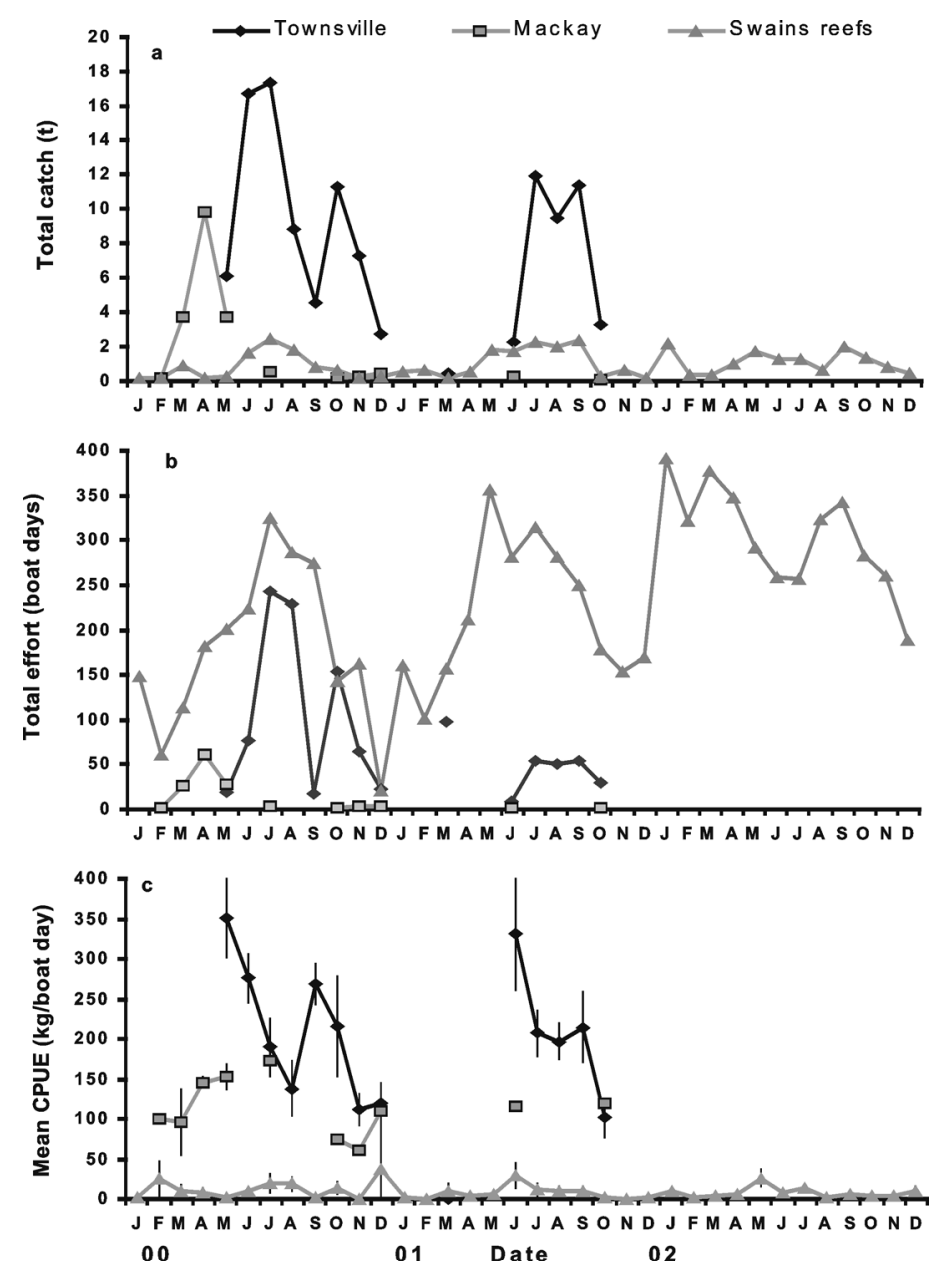

Fig. 2. a, Monthly total catch; b, total effort; and, c, catch per unit effort of Linuparus trigonus (Von Siebold, 1824), between January 2000 and December 2002 along Queenslands east coast. Logbook grids that reported $<0.3 \mathrm{t}$ per year $(<5 \%$ of reported catches) have been omitted for clarity.

proportion mature did not exceed 50\% until lobsters were larger than $80 \mathrm{~mm} \mathrm{CL}$, however, the frequency of ovigerous lobsters was highest in sizes of 75 to $85 \mathrm{~mm}$ CL (fig. 5). Lobsters possessing mature ovaries or ovigerous setae were present in all three locations sampled (see fig. 1).

Size-specific brood fecundity and egg size

The brood fecundity (BF) of 32 females varied from 19,287 to 100,671 eggs for females of 59.8 to $104.3 \mathrm{~mm}$ CL. Ovigerous females were obtained from August, October, February, March, and April. Brood fecundity was best described by the power equation, $\mathrm{BF}=0.1107 * \mathrm{CL}^{2.9241}\left(\mathrm{r}^{2}=0.74\right)$ (fig. 6). A double log-linear fit 


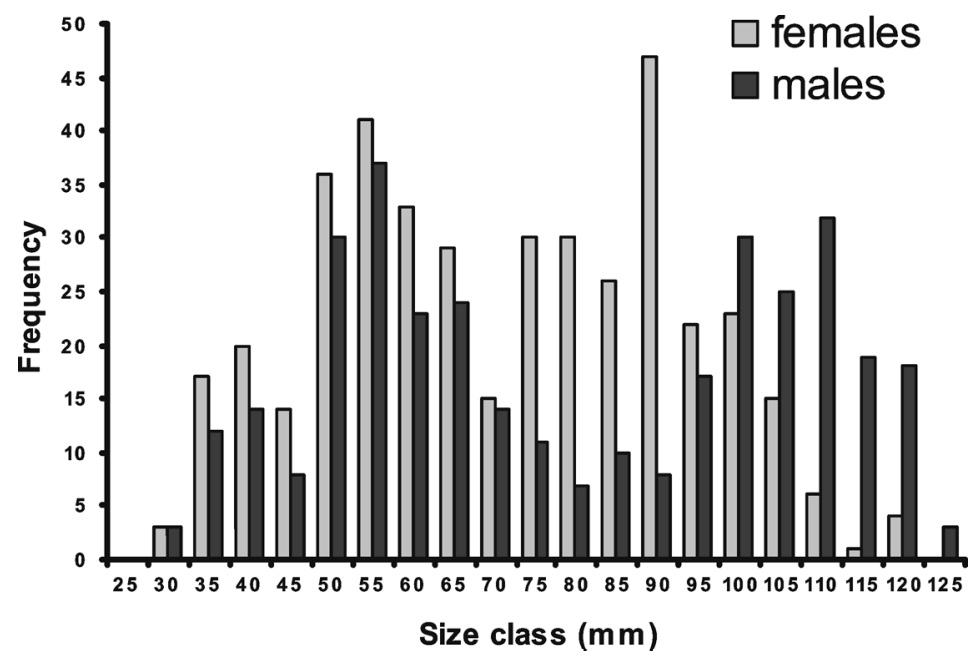

Fig. 3. Size frequency distributions of male and female Linuparus trigonus (Von Siebold, 1824).

Values on the $x$-axis are maximum values for each $5 \mathrm{~mm}$ size class interval.

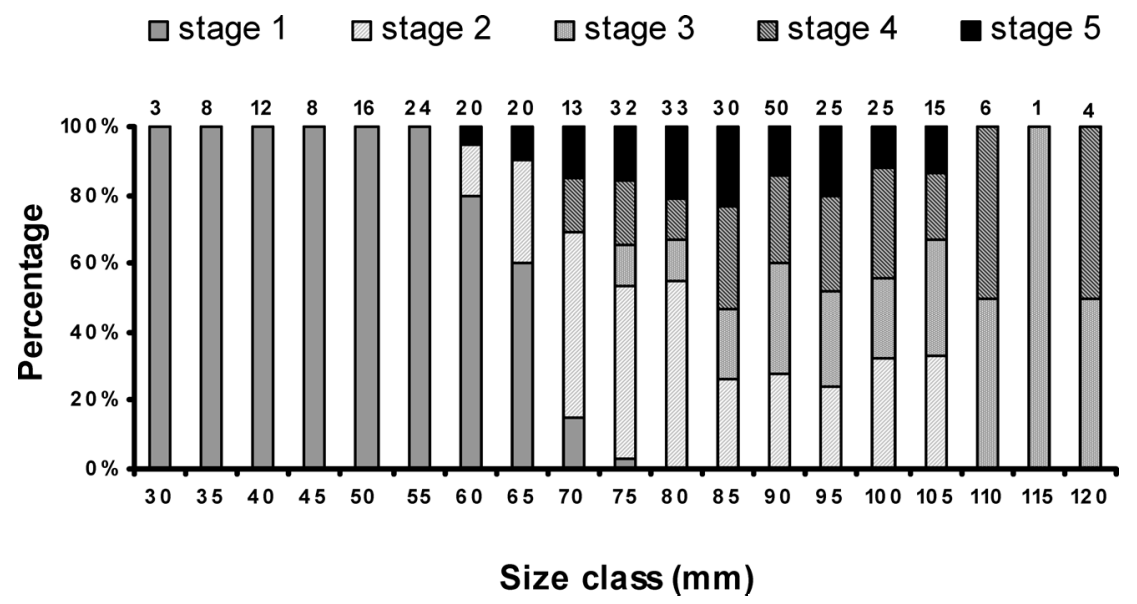

Fig. 4. Proportions of female Linuparus trigonus (Von Siebold, 1824), in relation to size and ovarian maturation as described in table I. Other details as for fig. 1.

$\left(\log _{10} \mathrm{BF}=2.7879 * \log _{10} \mathrm{CL}-0.6877, \mathrm{r}^{2}=0.66\right)$ of the data and raw linear fit $\left(\mathrm{BF}=1551.9 * \mathrm{CL}-79532, \mathrm{r}^{2}=0.63\right)$ had slightly lower $\mathrm{r}^{2}$ but are provided for comparison with most other lobster size-fecundity relations.

Egg size and weight ranged from 0.96 to $1.12 \mathrm{~mm}$ (mean $=1.02 \pm 0.01 \mathrm{~mm}$ ) and 0.28 to $0.77 \mathrm{mg}$ (mean $0.51 \pm 0.021 \mathrm{mg}$ ), respectively. Both egg weight and size were independent of lobster size. The mean number of eggs per gram body weight for ovigerous females was $245 \pm 10$ egg.g ${ }^{-1}$ (range 135-388). 


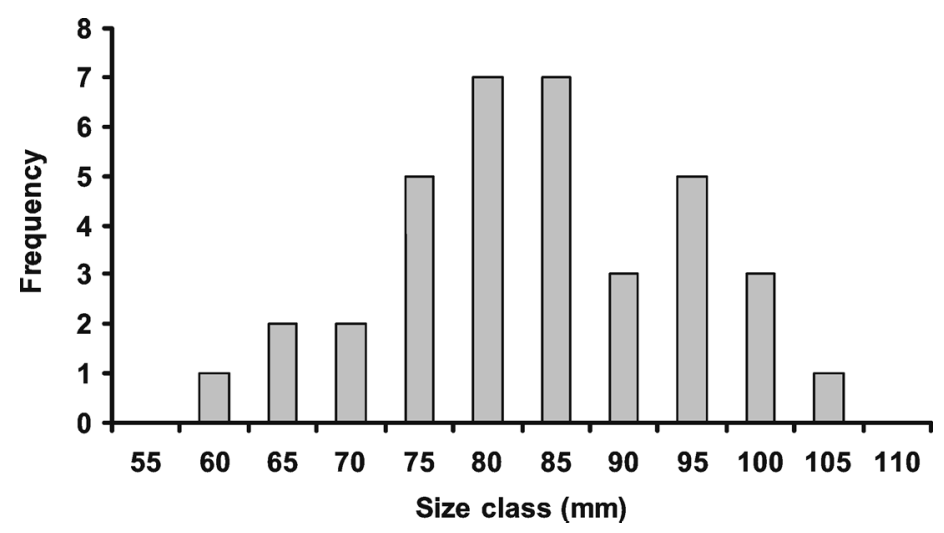

Fig. 5. Size frequency distribution of ovigerous Linuparus trigonus (Von Siebold, 1824). Other details as for fig. 1 .

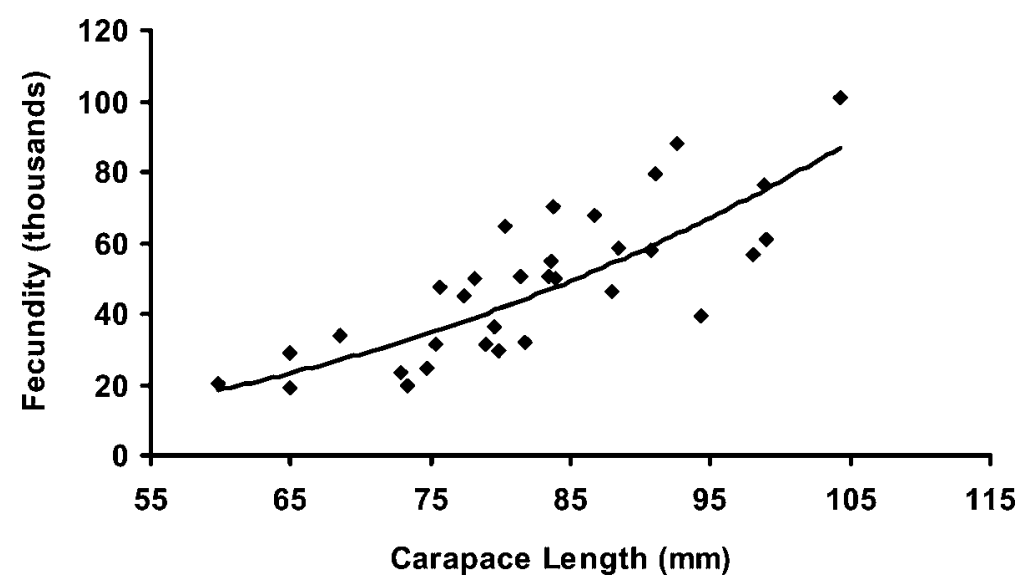

Fig. 6. Scatterplot regression of brood fecundity and carapace length of Linuparus trigonus (Von Siebold, 1824).

\section{DISCUSSION}

The results from this study are the first published accounts of brood fecundity for lobsters of the genus Linuparus. The minimum carapace size for which we were able to describe fecundity was limited to the smallest ovigerous female (59.8 mm CL). As no other females possessed mature gonads below this size and the largest ovigerous female was close to the maximum size encountered (only $2.8 \%$ of females were larger than $104 \mathrm{~mm} \mathrm{CL}$ ), the brood fecundity-size relationship is likely to represent the true limits of the species. The results indicated that ovigerous L. trigonus carry approximately 20,000-100,000 eggs and that the number of eggs in the brood is size dependent. The positive curvilinear relationship (fig. 6) between carapace length and brood fecundity in L. trigonus is similar 
to those described for other spiny lobsters (Chubb, 1994; Quackenbush, 1994). The broad geographical range that ovigerous and mature lobsters were collected from indicates that L. trigonus is reproductively active along Queensland's east coast between Townsville and Mooloolaba. Geographical variation in fecundity and size at maturity has been reported in several lobster species (Plaut, 1993; Chubb, 1994; Pollock, 1997; Mori et al., 1998). However, examination of the potential geographical differences in size at maturity and brood fecundity in L. trigonus is this study was not possible due to low sample numbers. Therefore, the brood fecundity-size relationship presented here should be viewed as a general relationship for Queensland's L. trigonus population.

Our findings that egg weight and egg size were independent of lobster size is consistent with other published lobster studies (Pollock, 1997; Stewart \& Kennelly, 1997; Demartini \& Williams, 2001). This indicates that, as suggested by Stewart \& Kennelly (1997), eggs from small lobsters are equally as viable as eggs from large lobsters. Comparisons of egg sizes between lobster species are usually represented as an inverse index of egg size and expressed as the number of eggs per gram body weight (Pollock, 1991, 1997). Results from the present study show that the mean number of eggs per gram body weight is relatively low $\left(250 \mathrm{egg} . \mathrm{g}^{-1}\right)$ compared to other spiny lobsters (300-800 egg.g ${ }^{-1}$; Pollock, 1997). Larger egg size in spiny lobsters is directly related to hatching phyllosoma size. The relatively large egg size of $L$. trigonus suggests that phyllosoma larvae exhibit some abbreviation of development. Linuparus phyllosoma hatch in an advanced stage, measuring between 2.40 and $2.55 \mathrm{~mm}$ at hatching, and therefore may have a short duration of larval development compared to other spiny lobster species (Kim, 1977; Baisre, 1994). Larval duration in deep water Palinurus spp. is markedly shorter than in the shallower Jasus and Panulirus spp., resulting in reduced larval mortality (Kittaka et al., 1997). Pollock (1997) suggested that the larger egg size in Palinurus spp. may be related to the deep water settling behaviour of the puerulus, which could subsequently reduce mortality rates of newly settled stages by reducing predation pressures. Interestingly, anecdotal evidence from commercial fishermen and unpublished research data (Ward, unpubl.) suggests that the abundance of small L. trigonus increases with depth. Ward (unpubl.) suggested that higher juvenile abundance with depth could be related to predation pressures decreasing with depth or result from a shoreward migration of juveniles after settlement in deeper waters off the continental shelf.

The smallest sexually mature lobster measured $59.8 \mathrm{~mm} \mathrm{CL}$ with $50 \%$ maturity (stages 3-5) between 80 and $85 \mathrm{~mm}$ CL. However, it is important to understand that due to the cyclic nature of gonad development in spiny lobsters (Kim, 1977; Aiken \& Waddy, 1980), stage 2 includes individuals maturing for the first time and mature lobsters in a regressed state of reproduction. Therefore, fig. 4 is likely 
to slightly overestimate the size at $50 \%$ maturity. Linuparus somniosus Berry \& George, 1972, mature at a much larger size than L. trigonus, with ovigerous females ranging from 96.1 to $130.9 \mathrm{~mm} \mathrm{CL}$ and $50 \%$ of females measuring above $110 \mathrm{~mm}$ CL ( $\mathrm{n}=14$; Wowor, 1999).

Some spiny lobsters are known to produce multiple broods, where the ovaries mature whilst the female is ovigerous (Minagawa \& Sano, 1997). In the present study all of the ovigerous females possessed spent ovaries, including mid and late stage ovigerous females. In Japanese waters, L. trigonus displays an annual reproductive pattern with the mean GSI peaking in July and falling to a minimum in November, with spawning occurring over 4 months between May and August (Kim, 1977). This suggests that L. trigonus in Japanese waters produces a single annual brood. However, as ovigerous animals were present over a broad temporal range in the present study (August, October, February-April), reproductive activity may be protracted in Queensland's population, possibly due to higher seawater temperatures. Further investigations are required to determine the seasonality of reproduction, incubation period, and brood frequency in Queensland's L. trigonus populations.

Results from the present study indicate that at the size of female maturity (>75 mm CL) females are more abundant than males. However, at larger size classes (>100 mm CL) males dominate. This could indicate that at the onset of sexual maturity female growth slows, resulting in males to numerically dominate the larger size classes. Gender related differences in growth rates have been reported for other spiny lobsters (Groeneveld, 1997; Hooker et al., 1997; McGarvey et al., 1999) and are usually related to mature females displaying longer intermoult periods and smaller moult increments than mature males (Aiken, 1980; Jong, 1993). Alternatively, behavioural changes at the onset of sexual maturity could result in reproductively active females being more susceptible to trawl capture, which could explain why females dominated between 75 and $95 \mathrm{~mm}$ CL.

The distribution of catches of $L$. trigonus highlights that this species is distributed along Queensland's east coast. The high catch rates off Townsville and Mackay indicate that in these areas lobster abundance is high enough to justify targeted fishery effort, however, effort in these areas is highly seasonal. In contrast to the L. trigonus trawl grounds off Townsville and Mackay, the catch rates at the Swain Reefs and southwards represent incidental catch whilst trawling for eastern king prawns Melicertus plebejus (Hess, 1865). Recent changes in the QECTF legislation prevent commercial trawlers from targeting L. trigonus. Consequently, in the target fisheries off Townsville and Mackay trawl effort has dropped markedly over the last three years and resulted in a significant reduction in the total reported catch of L. trigonus. Currently, the only management measure is a prohibition on retaining ovigerous females. Minimum legal sizes (MLS) are yet to be introduced 
as the optimum MLS is yet to be determined. MLS are often set to ensure lobsters breed at least once before recruitment to the fishery or at $50 \%$ maturity levels (Chubb, 1994). Tools which assist in determining appropriate MLS limits include yield and egg-per-recruit analyses, however, these methods require estimation of growth, natural mortality, and fishing mortality rates, which are currently unknown for L. trigonus. Therefore, future research on L. trigonus should concentrate on estimating these parameters as well as determining the seasonality of reproduction, the frequency of spawning, the percentage of egg loss during incubation, and larval survival.

\section{ACKNOWLEDGEMENTS}

This study was supported by the Australian Fisheries Research and Development Corporation Grant (2000/170) and the Queensland government. Thanks are extended to the commercial fishermen and processors, P. Duncan, G. Whitehouse, and R. Damon who generously donated samples and provided valuable catch location details. We are also thankful to Dr W. Sumpton for his regular discussions and critically reading this manuscript.

\section{REFERENCES}

Aiken, D. E., 1980. Moulting and growth. In: J. S. CobB \& B. F. Phillips (eds.), The biology and management of lobsters, 1: 91-163. (Academic Press, New York).

Aiken, D. E. \& S. L. Waddy, 1980. Reproductive biology. In: J. S. Cob \& \& B. F. Phillips (eds.), The biology and management of lobsters, 1: 215-276. (Academic Press, New York).

Berry, P. F. \& R. W. GeORge, 1972. A new species of the genus Linuparus (Crustacea, Palinuridae) from south-east Africa. Zool. Meded., Leiden, 46: 17-23.

BAISRE, J. A., 1994. Phyllosoma larvae and the phylogeny of Palinuroidea (Crustacea: Decapoda): a review. Australian Journ. mar. freshwat. Res., 45: 925-944.

Bruce, A. J., 1965. A new species of the genus Linuparus White, from the South China Sea (Crustacea Decapoda). Zool. Meded., Leiden, 41: 1-13.

Chub B, C. F., 1994. Reproductive biology: issues for management. In: B. F. PhilliPs, J. S. Coв B \& J. Kiтtak (eds.), Spiny lobster management: 181-212. (Blackwell Scientific Publications, Carlton, Victoria).

Demartini, E. E. \& H. A. Williams, 2001. Fecundity and egg size of Scyllarides squamosus (Decapoda: Scyllaridae) at Maro reef, northwestern Hawaiian Islands. Journ. Crust. Biol., 21: 891-896.

Groeneveld, J. C., 1997. Growth of spiny lobster Palinurus gilchristi (Decapoda: Palinuridae) off South Africa. South African Journ. mar. Sci., 18: 19-29.

Hill, B. J. \& T. J. Wassenberg, 1990. Fate of discards from prawn trawlers in Torres Strait. Australian Journ. mar. freshwat. Res., 41: 53-64.

Holthuis, L. B., 1991. FAO species catalogue 13. Marine lobsters of the world. An annotated and illustrated catalogue of the species of interest to fisheries known to date. FAO Fisheries Synopsis, 125: 111-114. (FAO, Rome). 
Hooker, S. H., A. G. Jeffs, R. G. Creese \& K. Sivaguru, 1997. Growth of captive Jasus edwardsii (Hutton) (Crustacea: Palinuridae) in north-eastern New Zealand. Mar. freshwat. Res., 48: 903-910.

JONG, K. J., 1993. Growth of the spiny lobster Panulirus homarus (Linnaeus, 1758), depending on sex and influenced by reproduction (Decapoda, Palinuridae). Crustaceana, 64: 18-23.

Kiм, C. H., 1977. Gametogenesis and early development of Linuparus trigonus (Von Siebold). Bull. Korean Fish. Soc., 10: 71-96.

Kittaka, J., A. Fernando \& A. Abrunhos A, 1997. Characteristics of palinurids (Decapoda; Crustacea) in larval culture. Hydrobiologia, 358: 305-311.

McGarvey, R., G. J. Fergus on \& J. H. Prescott, 1999. Spatial variation in mean growth rates and size of southern rock lobster Jasus edwardsii, in South Australian waters. Mar. freshwat. Res., 50: 333-342.

Minagawa, M. \& M. SAno, 1997. Oogenesis and ovarian development cycle of the spiny lobster Panulirus japonicus (Decapoda: Palinuridae). Mar. freshwat. Res., 48: 875-887.

Mori, M., F. BIAGi \& S. DE-RANIERI, 1998. Fecundity and egg loss during incubation in Norway lobster (Nephrops norvegicus) in the north Tyrrhenian Sea. Journ. nat. Hist., London, 32: 16411650.

Plaut, I., 1993. Sexual maturity, reproductive season and fecundity of the spiny lobster Panulirus penicillatus from the Gulf of Eilat (Aqaba), Red Sea. Australian Journ. mar. freshwat. Res., 44: 527-535.

Pollock, D. E., 1991. Population regulation and stock-recruitment relationships in some crayfish and lobster populations. In: A. Wenner \& A. Kuris (eds.), Crustacean egg production. Crustacean Issues 7: 247-266. (A. A. Balkema, Rotterdam).

— - 1997. Egg production and life-history strategies in some clawed and spiny lobster populations. Bull. mar. Sci., 61: 97-109.

QuACKenBush, L. S., 1994. Lobster reproduction: a review. Crustaceana, 67: 82-94.

Stewart, J. \& S. J. Kennelly, 1997. Fecundity and egg-size of the Balmain bug Ibacus peronii (Leach, 1815) (Decapoda, Scyllaridae) off the east coast of Australia. Crustaceana, 70: 191197.

— — \& — - 2000. Growth of the scyllarid lobsters Ibacus peronii and I. chacei. Mar. Biol., Berlin, 136: $921-930$.

Wowor, D., 1999. The spear lobster, Linuparus somniosus Berry \& George, 1972 (Decapoda, Palinuridae) in Indonesia. Crustaceana, 72: 673-684.

First received 16 June 2003.

Final version accepted 5 August 2003. 